\title{
SRI LANKAN DENTAL PROFESSIONALS' KNOWLEDGE OF THE CORONA VIRUS DISEASE-19 (COVID-19): A QUESTIONNAIRE SURVEY
}

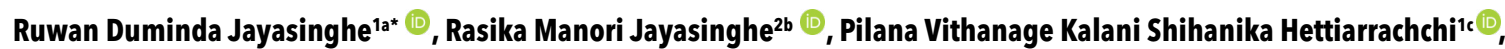 \\ Lakshman Perera Samaranayake ${ }^{3 d}$ (D)
}

${ }^{1}$ Department of Oral Medicine and Periodontology, Faculty of Dental Sciences, University of Peradeniya, Peradeniya, 20400 Sri Lanka

2Department of Prosthetic Dentistry, Faculty of Dental Sciences, University of Peradeniya, Peradeniya, 20400 Sri Lanka

${ }^{3}$ Department of Oral Biosciences, Faculty of Dentistry, University of Hong Kong, Hong Kong

aBDS, MS, Professor, Chair; e-mail: ruwanja@dental.pdn.ac.lk; ORCIDiD: https://orcid.org/0000-0002-8054-4301

bBDS, MS, Senior Lecturer, Head; e-mail: manorija@dental.pdn.ac.lk; ORCIDiD: https://orcid.org/0000-0001-5878-4985

'BDS, MD, Senior Lecturer; e-mail: kalaniz2004@yaho0.com; ORCIDiD: https://orcid.org/0000-0003-2618-5050

${ }^{d}$ DSC, DDS (Glas), FRCPath, FDSRCS(Edin), FRACDS, FDS RCPS (Glas), FHKCPath, FCDSHK, Professor Emeritus; e-mail: lakshman@hku.hk;

ORCIDiD: https://orcid.org/0000-0002-9122-336X

\section{ABSTRACT}

do) https://doi.org/10.25241/stomaeduj.2021.8(1).art. 1

Background Dental practitioners are some of the most vulnerable professionals exposed to the risk of contracting the Corona Virus Disease-19 (COVID-19), by virtue of the aerosol generating procedures (AGPs). Hence, an evidence based and detailed knowledge of the disease is important in order to mitigate the effects of the COVID-19 transmission.

Aim To identify the perspective, knowledge, and attitudes of Sri Lankan dental surgeons on the COVID-19 pandemic.

Methods An online web-based, self-administered questionnaire survey (Google) was conducted among Sri Lankan dental surgeons. All questions, in the pre-tested questionnaire were close-ended, and formulated to elicit data on the views, knowledge, attitudes, and infection control practices related to the COVID-19 pandemic.

Results One quarter of the cohort responded and the majority (44.7\%) were 30-40 years old with a marginal female preponderance (52.3\%). In general, females were significantly more knowledgeable than males on COVID-19, and the post-pandemic preparedness for dental practice $(p<0.05)$. One sixth $(18.2 \%)$ incorrectly surmised that, i) pet animals were a source of infection, ii) COVID-19 is not transmitted via surface contact and iii) hand hygiene is not important in preventing infection transmission. All respondents correctly identified AGPs as a high-risk procedure for infection transmission, but approximately two thirds failed to identify specific AGPs in dentistry.

Conclusion Taken together, the knowledge, attitudes and practices of Sri Lankan dental surgeons on the COVID-19 pandemic appear satisfactory, but there are knowledge gaps that need to be fulfilled through further continuous education courses.

\section{KEYWORDS}

COVID 19; Dental Practice; Knowledge; Dental Surgeons.

\section{INTRODUCTION}

The first case of Corona Virus Disease-19 (COVID-19) caused by the severe acute respiratory syndrome corona virus 2 (SARS-CoV-2) was reported in Wuhan, China in December 2019 [1]. Even though scant attention was paid to the disease at the time, within weeks it became a serious health concern leading to an epidemic spread in China, prior to the subsequent pandemic spread the world over. COVID-19 was declared a public health emergency of international concern by the World Health Organization on 30th of January 2020 [2]. As of this writing, in December 2020, the number of COVID-19 cases worldwide

(c) (1) (2) OPEN ACCESS This is an Open Access article under the CC BY-NC 4.0 license Peer-Reviewed Article

Citation: Jayasinghe RD, Jayasinghe RM, Hettiarrachchi PVKS, Samaranayake LP. Sri Lankan dental professionals' knowledge of the Corona Virus Disease-19 (COVID-19): a questionnaire survey. Stoma Edu J. 2021;8(1):7-17

Received: December 19, 2020; Revised: January 10, 2021; Accepted: January 23, 2021; Published: January 28, 2021

*Corresponding author: Prof. Ruwan Duminda Jayasinghe

Department of Oral Medicine and Periodontology, Faculty of Dental Sciences, University of Peradeniya, Peradeniya, 20400 Sri Lanka

Tel/Fax: 094 812397451; e-mail: ruwanja@dental.pdn.ac.lk

Copyright: $\odot 2021$ the Editorial Council for the Stomatology Edu Journal 


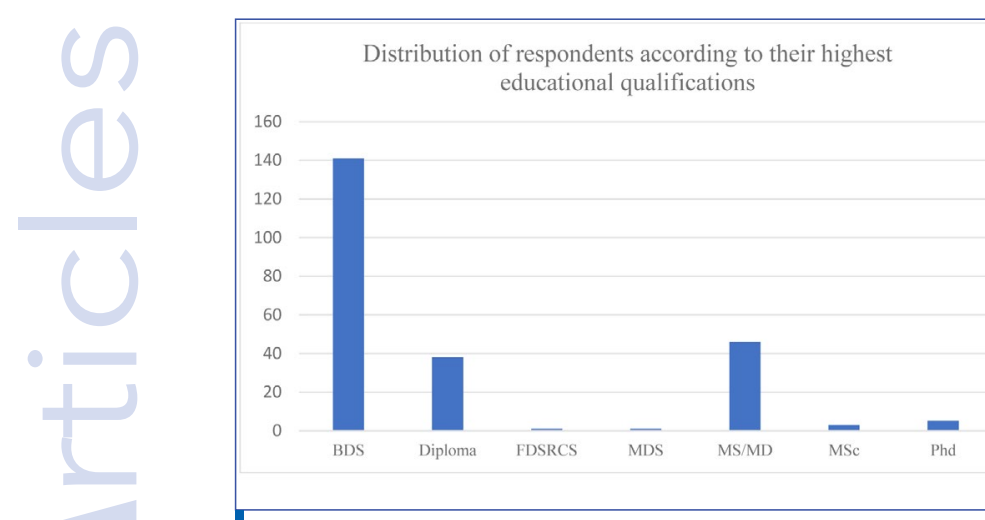

Figure 1. Distribution of respondents according to the highest educational qualifications.

COVID-19 cases worldwide has surpassed 75 million, with over 1.6 million deaths [3]. In Sri Lanka, the first case of COVID-19, was reported in a Chinese tourist, in January 2020, and the first, communally transmitted patient reported two months later; at the time of writing (December 2020), Sri Lanka has over 36,000 confirmed cases, with 165 reported deaths. SARS-CoV-2 primarily spreads via droplets produced by coughing, sneezing, and talking. When droplets are large and heavy, they usually fall to the ground or onto surfaces, but the smaller particles, called aerosols, are entrained in the air for prolonged periods of approximately 3 hours if the ambient circulation is stagnant $[4,5]$. A substantial proportion of dental procedures entail aerosol generation due to the high speed instrumentation accompanied by air/water coolants, and hence dentistry is considered a high risk profession in terms of contracting air borne diseases such as COVID-19 [6]. Furthermore, experience from previous epidemics such as the severe acute respiratory syndrome (SARS) has shown the susceptibility of health care providers, including dental health care workers to the risk of possible infection [7]. In order to protect dental professionals, and their patients from COVID-19, many national bodies, including the Sri Lanka Dental Association, have issued guidelines on infection control in dental settings to the profession at large [6,7]. Nevertheless, there has been little follow up after such promulgations and, no feedback elicited from dentists on the adherence to, and implementation of these guidelines in clinical practice. Clearly, such feedback is helpful in rectifying deficiencies, and preparing for future emergencies. Hence the main aim of the current questionnaire survey was to identify the views, knowledge and attitudes of Sri Lankan dental surgeons on the current COVID-19 pandemic through a web-based questionnaire survey. A particular focus of the survey was to evaluate the adherence to the COVID- 19 protective measures and awareness of methods of SARS-CoV-2 transmission, infection control precautions that need to be implemented during the pandemic, and the challenges associated with their implementation.

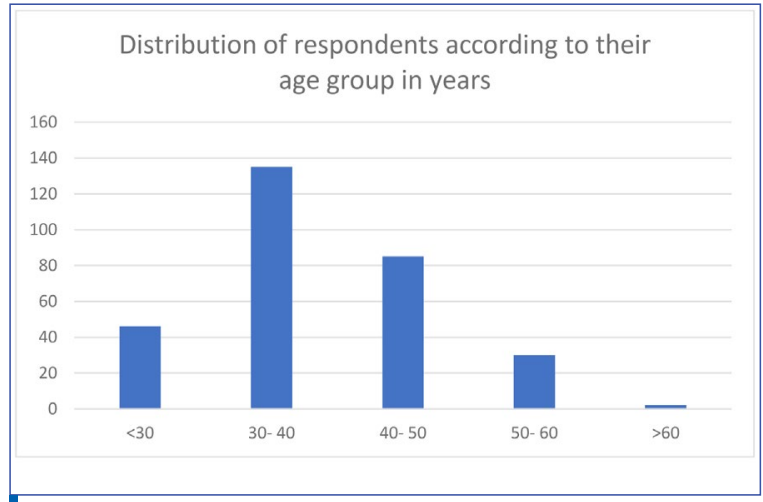

Figure 2. Distribution of respondents according to the age group.

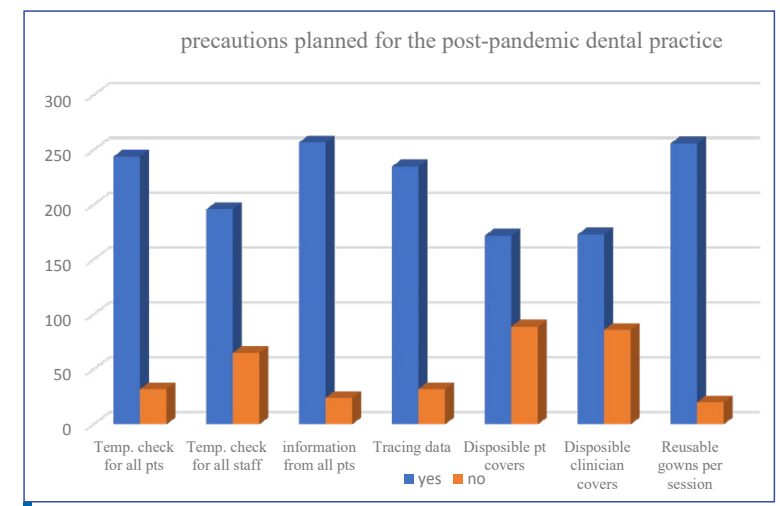

Figure 3. Details of precautions planned by the respondents for the postpandemic dental practice.

\section{METHODS}

An online web-based questionnaire survey was conducted among dental specialists and dental surgeons in Sri Lanka. Those with access to the World Wide Web, both in the government service and in private practice, were included in the study. A selfadministered pre-tested Google form (Appendix 1) was used as the study instrument.

The questionnaire, formulated by the authors (LPS, RJ), was first pre-tested among a group of 10 dental surgeons to ensure clarity of interpretation, and ease of completion by the participants. The questionnaire, of all close-ended questions, comprised demographic data and specific questions on the views, knowledge and attitudes of Sri Lankan dental surgeons on the current COVID-19 pandemic. The pre-tested questionnaire was then converted into a Google form and the survey link was disseminated as a Uniform Resource Locator (URL) web address among the cohort, via social media and email. A cover letter was included with the questionnaire, which described the purpose of the study and its outline, and instructions were given on completing the questionnaire; the confidentiality and anonymity of the data provided were assured. The data management and statistical analyses were performed using the statistical software SPSS version 21.0. Frequencies and percentages were obtained for categorical data, and Chi-square test was used to determine the association between variables. 
I Table 1. Comparison of $\mathrm{P}$ values highlighting statistical significance between respondents' gender, age groups and highest educational qualifications with knowledge of COVID- 19 and its impact on dental practice.

\begin{tabular}{|l|l|l|l|}
\hline \multicolumn{1}{|c|}{ Question } & \multicolumn{1}{|c|}{$\begin{array}{c}\text { Sex } \\
\text { (P) }\end{array}$} & $\begin{array}{c}\text { Age } \\
\text { group (p) }\end{array}$ & $\begin{array}{c}\text { Education } \\
\text { (p) }\end{array}$ \\
\hline Incubation period of COVID 19 infection? & 0.000 & 0.412 & 0.249 \\
\hline $\begin{array}{l}\text { Attendance to webinars or continuing education programs on maintaining dental practices } \\
\text { during COVID-19 pandemic }\end{array}$ & 0.000 & 0.361 & 0.305 \\
\hline Believe patients with chronic diseases run a higher risk of contracting COVID 19? & 0.000 & 0.643 & 0.409 \\
\hline Believe older patients are at a higher risk for COVID 19 infections? & 0.000 & 0.566 & 0.401 \\
\hline Believe mortality rate for the young population is zero? & 0.000 & 0.074 & 0.315 \\
\hline Covid-19 transmission & 0.000 & 0.476 & 0.000 \\
\hline Prevented by good hygiene practices? & 0.000 & 0.655 & 0.369 \\
\hline Minimum social distance advised to prevent COVID-19 spread? & 0.000 & 0.691 & 0.780 \\
\hline Loss of taste and loss of smell as early symptoms of COVID-19 & 0.000 & 0.243 & 0.420 \\
\hline
\end{tabular}

$P$ level $<0.05$ was considered significant). Ethical clearance for the study was obtained from the Ethics Review Committee of the Faculty of Dental Sciences, University of Peradeniya, Sri Lanka.

\section{RESULTS}

\subsection{Demographic and personal information}

The survey was transmitted to a cohort of 1598 dental surgeons, of which $302(25 \%)$ responded. Most respondents were aged $30-40$ years (44.7\%), with a marginally female preponderance $(52.3 \%)$. Two thirds of the respondents were dental surgeons $(n=120)$ working in the dental clinics of the Ministry of Health, Sri Lanka, with the rest, though employed by the Ministry of Health, were concurrently engaged in private practice. Most of the respondents had only the primary qualification of BDS $(n=177)$ while $45(15 \%)$ also had a postgraduate diploma; 60 were specialists with anMD/ MS degree (Fig. 1). Questioned on the attendance and participation in continuing education programs during the COVID-19 pandemic, a majority (60\%) responded in the affirmative. Of these, $74 \%$ were respondents younger than $30(p<0.05)$.

\subsection{Knowledge and belief related to COVID-19 patient identification}

The vast majority of the respondents ( $91 \%$ ) was aware of the incubation period for SARS-CoV-2 infection as 2-3days, but that it may take up to 21 days. Almost all of the respondents (96\%) under 30 provided an accurate response to this question. All participants identified at least one symptom of the infection, while $18 \%$ identified all the stated symptoms of the disease. Similarly, $96 \%$ of the respondents believed that patients with chronic diseases run a higher risk of contracting COVID-19. Awareness that older populace run a higher risk of contracting the COVID-19 than the younger individuals was also very high (97\%) and only $4 \%(12 / 302)$ respondents incorrectly believed that the mortality rate for young population is zero (Table 1).

\subsection{Knowledge regarding transmission of COVID-19}

All respondents were aware that the aerosol generating procedures (AGPs) were a high risk activity for the infection transmission, but only one third (39\%), accurately identified that implants placement, scaling and restorative procedures as high risk interventions that may transmit the infection (Table 1).

Surprisingly, a sixth of the respondents $(55 / 302 ; 18.2$ $\%)$ incorrectly surmised that, i) pet animals were a source of infection, ii) COVID-19 is not transmitted via surface contact and iii) hand hygiene is not important in preventing infection transmission. Nevertheless, $82 \%$ were aware that the infection spreads through droplets or nasal discharge $(p<0.05)$. Further, $93 \%$ of the respondents believed that COVID-19 infection can be transmitted through the fluid of an infected person $(p<0.05)$. Nearly $85 \%$ have correctly identified 1 meter as the minimum social distance to be kept in order to minimize transmission of infection.

\subsection{Preparedness in treating dental patients during and post pandemic period}

Most of the participants (92.4\%) had purchased personal protective equipment, but two-fifths (40.4\%) did not possess N95 masks. Almost two thirds of the respondents (62.3\%) had treated emergency patients during the peak month from 15th March to 15th April 2020 when Sri Lanka was under the lockdown. One half of the respondents $(52.2 \%)$ were confident of starting dental practice once the pandemic subsided, whereas $25.2 \%$ were hesitant, and $6 \%$ were not confident in doing so. Although over $92 \%$ have been provided with personal protective equipment (PPE), only $57 \%$ had access to $\mathrm{N} 95$ masks during the initial period of the COVID-19 pandemic. All respondents were planning to implement precautions during the post-pandemic 
ITable2. Percentage of responses regarding knowledge and plan of the respondents to start dental practice during and post COVID-19 pandemic.

\begin{tabular}{|c|c|}
\hline Questions in the questionnaire & $\%$ \\
\hline $\begin{array}{l}\text { Can disease be prevented by good hygiene practices? } \\
\text { Yes } \\
\text { No }\end{array}$ & $\begin{array}{c}95 \\
3\end{array}$ \\
\hline $\begin{array}{l}\text { What is minimum social distance advised to prevent COVID-19 spread? } \\
1 \mathrm{~m} \\
1.5 \mathrm{~m} \\
2 \mathrm{~m} \\
2.5 \mathrm{~m}\end{array}$ & $\begin{array}{l}84.4 \\
4.3 \\
8.6 \\
1.3\end{array}$ \\
\hline $\begin{array}{l}\text { Are you aware that loss of taste and loss of smell are early symptoms of COVID-19 } \\
\text { Yes } \\
\text { no }\end{array}$ & $\begin{array}{l}86.8 \\
12.6 \\
\end{array}$ \\
\hline $\begin{array}{l}\text { How important is it to know the patient's residential area when taking the history? } \\
\text { Highly important } \\
\text { Not important } \\
\text { May be important }\end{array}$ & $\begin{array}{l}91.4 \\
6.6 \\
0.7\end{array}$ \\
\hline $\begin{array}{l}\text { Will you consider patient's travel history before treating him? } \\
\text { Yes } \\
\text { No } \\
\text { May be }\end{array}$ & $\begin{array}{c}97.7 \\
1 \\
1.3\end{array}$ \\
\hline $\begin{array}{l}\text { How confident are you about starting your dental practice after the pandemic? } \\
\text { Highly confident } \\
\text { Confident } \\
\text { Hesitant } \\
\text { Not confident }\end{array}$ & $\begin{array}{l}12.6 \\
52.3 \\
25.2 \\
6.0\end{array}$ \\
\hline $\begin{array}{l}\text { What is your biggest fear on starting your post-pandemic dental practice? (Select ALL that apply) } \\
\text { Increased cost of care delivery } \\
\text { Risk of contracting disease from patients } \\
\text { Limited resources including PPE }\end{array}$ & $\begin{array}{l}5.41 \\
36.2 \\
58.6\end{array}$ \\
\hline $\begin{array}{l}\text { Will you ask your patient to get tested for Covid-19 before treatment? } \\
\text { Yes, all the patients for aerosol generating procedures } \\
\text { No } \\
\text { May be, only if patient is symptomatic }\end{array}$ & $\begin{array}{l}10.9 \\
18.2 \\
70.9\end{array}$ \\
\hline $\begin{array}{l}\text { How worried are you about Medico Legal issues once you open up your dental practice? (1 not worried, } 5 \\
\text { extremely worried) Rate from } 1 \text { to } 5 \\
1 \\
2 \\
3 \\
4 \\
5\end{array}$ & $\begin{array}{l}11.3 \\
11.3 \\
38.4 \\
17.9 \\
19.9\end{array}$ \\
\hline
\end{tabular}

practice. The majority were to introduce temperature checks for all patients (88.4\%), and the staff (75\%), but planned use of reusable gowns per each session and of disposable over wear for both patients and clinicians were low (Fig. 3). Ninety one percent of the respondents felt it is highly important to know the residential area of the patients, while $97.7 \%$ thought knowing the patient's travel history is important before treating them. The highest fear among the respondents to start dental practice was the limited availability of resources for protection such as PPE (Table 2). The answers covering the respondents' knowledge on the pandemic and the plans in relation to the maintenance of post-pandemic dental practice were analyzed according to their gender, and females almost always responded better than males $(p<0.05)$. In terms of the age group, the plans for triage of the clinic attendees, was highest for the 36- 45 years age group $(p<0.05)$ (Table 3$)$.

\section{DISCUSSION}

The unprecedented COVID-19 pandemic caused by SARS-CoV-2 has taken the world by surprise. It is now clear that aerosols are the main mode of COVID-19 transmission, and dentistry, being an important branch of health care has come under intense scrutiny due to the many AGPs that entail clinical dental practice. Hence, infection control procedures in dentistry have been freshly reviewed with revised guidelines promulgated by various bodies including US Centers for Disease Control [8]. A good awareness and knowledge of the mode of transmission of COVID-19 among dental professionals is essential to implement these guidelines. Although a number of reports are available on the dentists' awareness of the pandemic and attitudes towards the implementation of clinical guidelines $[9,10]$ no such data are available from Sri Lanka. Hence, we conducted 
I Table 3. Comparison of $P$ values highlighting statistical significance between respondents' gender, age groups and highest educational qualifications with their plan for patient handling at the dental practice during COVID-19 pandemic and post pandemic period.

\begin{tabular}{|c|c|c|c|}
\hline & $\begin{array}{c}\text { Sex } \\
\mathbf{p}\end{array}$ & $\underset{\text { group (p) }}{\text { Age }}$ & $\begin{array}{l}\text { Education } \\
\text { (p) }\end{array}$ \\
\hline Do you triage your patients? & 0.000 & 0.013 & 0.071 \\
\hline Will you consider patient's travel history before treating him? & 0.000 & 0.206 & 0.846 \\
\hline How important is it to know the patient's residential area when taking the history? & 0.000 & 0.257 & 0.009 \\
\hline Have you purchased / provided with Personal Protection Equipment (PPE) kits? & 0.000 & 0.795 & 0.668 \\
\hline Do you have access to purchase / provided with N95 masks? & 0.000 & 0.154 & 0.415 \\
\hline Have you treated emergency patients during the month from 15th March to 15 th April? & 0.000 & 0.974 & 0.821 \\
\hline Have you treated emergency patients during the month from 16th April to 15th May? & 0.000 & 0.910 & 0.192 \\
\hline Have you treated emergency patients after 16 th of May? & 0.000 & 0.368 & 0.297 \\
\hline How confident are you about starting your dental practice after the pandemic? & 0.000 & 0.151 & 0.327 \\
\hline Will you ask your patient to get tested for Covid-19 before treatment? & 0.000 & 0.202 & 0.202 \\
\hline $\begin{array}{l}\text { US centers for disease control (CDC), and many dental associations including SLDA have } \\
\text { proposed guidelines for COVID-19 prevention in dental clinics. }\end{array}$ & 0.000 & 0.946 & 0.750 \\
\hline $\begin{array}{l}\text { Precautions planning at the post-pandemic practice } \\
\text { 1.Temperature checking of all patients }\end{array}$ & 0.054 & 0.179 & 0.324 \\
\hline 2.Temperature checking of all staff before they start work & 0.066 & 0.552 & 0.430 \\
\hline 3. Information form on COVID-19 to all patients & 0.002 & 0.894 & 0.894 \\
\hline 4. Tracing data & 0.013 & 0.805 & 0.519 \\
\hline 5. Disposable Patient covers & 0.000 & 0.687 & 0.513 \\
\hline 6. Disposable clinician covers changed for each patient & 0.000 & 0.497 & 0.577 \\
\hline 7. Reusable gown worn for session/ day & 0.052 & 0.194 & 0.730 \\
\hline 8. Will you edit the patient history questionnaire & 0.000 & 0.599 & 0.816 \\
\hline 9. Will you question the patient on recent loss of taste or smell? & 0.005 & 0.073 & 0.05 \\
\hline
\end{tabular}

the current electronic, online survey to elicit the knowledge and practices of 1598 dental surgeons and dental specialists working in the public and private sector in Sri Lanka [11]. A pre-tested questionnaire was sent via email to the cohort and open invitations for response were posted in the social media platforms, including Facebook and specific groups created among dental surgeons. Our study demonstrated a relatively poor response rate with only a quarter (25\%) of the dental surgeons and specialists responding to the questionnaire. Low response rates are common in electronic questionnaire surveys and non-respondent bias may have affected the outcome of our results. Given this caveat, the findings of our survey shed light on the knowledge of, and attitudes to infection control in Sri Lankan dental surgeons during the pandemic period. Overall, a large majority of respondents had envisioned and anticipated the impact of COVID-19 on their clinical practices, as they demonstrated a very satisfactory knowledge of the disease symptomatology and preventive measures. It was encouraging to note that most of them attended webinars to improve their knowledge of COVID-19, in contrasts to a recent similar study from Turkey that has shown low attendance rates at continuing education courses by dentists [12].

Prevention of COVID-19 is mainly achieved by proper hand washing, social distancing and by respiratory protective measures such as the use of face masks/ face shields [13]. In contrast to the findings of other similar surveys [10,12], almost a fifth of our respondents incorrectly mentioned that hand hygiene is not important in preventing infection and pet animals are a major source of infection. Personal protective equipment (PPE) is an essential prerequisite for the safe delivery of dental care, as well as for the protection of the dental surgeon and the dental team. A number of organizations including the US Centers for Disease Control [8] and the Sri Lanka Dental Association [6] have emphasized the importance of PPE in dentistry. PPE include gloves, respirators or face masks, face shields or goggles and protective clothing [14]. Most of the respondents (92.4\%) in our survey had purchased PPE, but only $60 \%$ had $\mathrm{N} 95$ masks. This is better than the figures reported in similar studies on Indian and Turkish dentists, respectively $[12,15]$. As fever is one of the demonstrable early symptoms of COVID-19, dental health care providers must as a routine, 
measure the patients' body temperature as well as those of his staff and him/herself, prior to entering the clinic premises [14]. The majority were aware of this recommendation as $80 \%$ were planning to measure the temperature of the patients, and $65 \%$ in both the patients as well as the staff.

As a health care worker, it is the solemn duty of a dental surgeon to provide essential and emergency care to patients, irrespective of the pandemic circumstances. Hence it was heartening to note that some two thirds of the respondents (62.3\%) managed patients with dental emergencies during the island-wide, lock-down period in Sri Lanka (from 15th March to 15th April 2020). This is in contrast to only one fifth of the dentists $(22.8 \%)$ in India who rendered such emergency services during a similar lock-down period in India [15].

It is the general consensus that COVID-19 pandemic is unlikely to subside in the immediate term, and is likely to smolder, and remain as an endemic disease in most regions of the world for the foreseeable future. Yet, dental professionals, like all other similar care providers, need to maintain their services to the public while taking the necessary precautions to minimize infection spread. Due to the high levels of morbidity and mortality associated with COVID-19, there is nevertheless a reluctance, fear and anxiety amongst dentists to return to work, as shown in some recent studies $[9,15]$. This was clearly expressed in our survey, as one fourth of responding dental surgeons were hesitant to start their postpandemic dental practice in the short term, and $6 \%$ were not confident in doing so at all. However, it was heartening to note that approximately, one half of the respondents (52.4\%) were very confident in returning to work after the lock-down period. This number is significantly higher than the figure reported by Kinariwala et al., where 54.3\% of respondents in their study were not confident, and $35.7 \%$ were hesitant to commence their postpandemic dental practices [15]. In addition, the availability of COVID-19 vaccines in the near future, for countries such as Sri Lanka, should help improve the prospects of dentists returning to work without much ambivalence.

\section{CONCLUSIONS}

In general, the knowledge, attitudes and practices of Sri Lankan dental surgeons on the COVID-19 pandemic appear satisfactory but there are significant gaps in their knowledge that need to be addressed such as the knowledge on the method of transmission. Highest fear among the respondents was limited availability of resources to practice dentistry. Health authorities and professional associations need to consider these factors when preparing guidelines for the management of patients in the dental clinics during the pandemic. Gender as well as educational qualifications-related differences were noted in some responses. Our survey highlights the importance of continuing education and further educational programs on COVID-19 for dental professionals in Sri Lanka.

\section{CONFLICT OF INTEREST}

The authors declare no conflict of interest.

\section{ACKNOWLEDGMENTS}

We like to thank all the dental surgeons who helped disseminate and respond to the questionnaire during a difficult period.

\section{AUTHOR CONTRIBUTIONS}

RDJ: plan the study, plan the questionnaire and assisted in data collection and did the first draft. RMJ: was involved with the data collection, preparation of questionnaire, statistical analysis and finalizing the manuscript. PKH: was involved with the data collection, preparation of questionnaire and finalizing the manuscript. LPS: came up with the idea, assisted in preparation of questionnaire, supervise the project and assisted in finalizing the manuscript. 


\section{Annex 1 \\ Knowledge and Practices among Sri Lanka Dental Surgeons on Professional Dental Practice during the Corona virus Disease-2019 (COVID-19) Pandemic}

Serial No.

\section{Demographic and personal information}

1. Gender- Male Female

2. Nationality Sri Lankan $\square$ Any other (PI specify)

3. Your specialty
$\square$ General practitioner
$\square$ Consultant in Restorative Dentistry
Consultant in Orthodontics
$\square$ Consultant in Oral and Maxillofacial Surgery
$\square$ Consultant in Community Dentistry
Trainee in Restorative Dentistry Trainee in Orthodontics
Trainee in Oral and Maxillofacial Surgery
Trainee in Community Dentistry

Any other (PL specify)

4. Your education B.D.S $\square$ Diploma $\square$ MS/MD $\square$ any other (pl specify)
5. Age (in years) $<30$ $30-40$ $40-50$ $50-60$ $>60$

6. What best describes the type of practice you are in? (Select ALL that apply) Ministry of Health $(\mathrm{MOH}) \square$ Academic $\square$ Private Practice $\square$

7. Did you attend webinars or continuing education programs on maintain/ conducting dental practices during COVID-19 pandemic? Yes

\section{Knowledge and belief related to COVID-19 patient identification}

8. What is incubation period of COVID 19 infection?

1 day

$\square$ 2-3 days but may take up to 21 days

28 days 
1. Which are the symptoms of COVID 19 infection? (Select ALL that apply)
Fever
Dry cough
Tiredness
Nasal congestion
Diarrhea
Aches and pains
None of the above
All of the above

2. Do you believe that patients with chronic diseases run a higher risk of contracting COVID 19? Yes No

3. Do you believe that older patients are at a higher risk for COVID 19 infections? Yes No

4. Do you believe mortality rate for the young population is zero? Yes No

\section{Knowledge regarding transmission of COVID-19}

5. Which dental procedures do you consider as high risk to transmit COVID 19

$\square$ History taking and Examination
$\square$ Dental Extraction
$\square$ Scaling
$\square$ Restorative procedures
$\square$ Providing dentures
$\square$ Implant placement

6. Which of the following statement is TRUE? (Select ALL that apply)

$\square$ Pet animals are the biggest source of infection.

$\square$ Covid-19 spreads through droplets of saliva or nasal discharge.

$\square$ Covid-19 is not transmitted via surface contact.

$\square$ Hand hygiene is not important to prevent transmission of Covid-19.

7. Do you believe Covid-19 infection can spread through fluid of infected person? Yes No $\square$

8. Can the disease be prevented by good hygiene practices? Yes No

9. What is the minimum social distance advised to prevent COVID-19 spread? 1 meter $1.5 \mathrm{~m}$ $2 m$ $2.5 \mathrm{~m}$ 
10. Are you aware that loss of taste and loss of smell are early symptoms of COVID-19:

Yes $\square$ No $\square$

\section{History taking practice}

How important is it to know the patient's residential area when taking the history?

Highly important $\square$ Not important $\square \quad$ may be important $\square$

11. Will you consider the patient's travel history before treating him?

Yes $\square$ No $\square$ May be $\square$

12. Do you triage your patients?"Yes $\square$ No $\square$

\section{Fears associated with the best management practices}

13. Have you purchased / provided with Personal Protection Equipment kits?

Yes $\square$ No $\square$

14. Do you have access to purchase / provided with N95 masks? Yes No

15. Have you treated emergency patients during the month from $15^{\text {th }}$ March to $15^{\text {th }}$ April? Yes $\square$ No $\square$

16. Have you treated emergency patients during the month from $16^{\text {th }}$ April to $15^{\text {th }}$ May? Yes $\square$ No

17. Have you treated emergency patients after $16^{\text {th }}$ of May? Yes No

18. How confident are you about starting your dental practice after the pandemic? Highly confident Confident Hesitant Not confident at all

19. What is your highest fear on starting your post-pandemic dental practice? (Select ALL that apply)

Limited availability of personal protection kits

$\square$ Limited resources to sterilize/disinfect the equipment and the clinic premises

$\square$ Risk of contacting infection from the patient

\section{Increased operating cost and unaffordable cost of care delivery}

20. Will you ask your patient to get tested for Covid-19 before treatment?

$\square$ Yes, all the patients for aerosol generating procedures should get themselves tested.

$\square$ No

May be, only if patient is symptomatic 
1. How worried are you about Medico-Legal issues once you open up your dental practice? (1 not worried, 5 extremely worried)

Rate from 1 to 5

2. US centers for disease control (CDC), and many dental associations including SLDA have proposed guidelines for COVID-19 prevention in dental clinics.

a. Are you aware of these guidelines Yes $\square \quad$ No

b. Do you follow all the guidelines so proposed?

Always $\square$ Sometimes $\square$ Rarely $\square$ Never

3. What precautions are you planning at the post-pandemic practice

1. Temperature checking of all patients: Yes $\square$ No

2. Temperature checking of all staff before they start work: Yes

No

3. Information form on COVID-19 to all patients: Yes

No

4. Tracing data: Yes No

5. Disposable Patient covers: Yes No

6. Disposable clinician covers changed for each patient: Yes No

7. Reusable gown worn for session/ day: Yes No $\square$

28. Will you edit the patient history questionnaire? Yes No

29. If yes to question 28 above:

a) Will you insert an immediate travel history question ( 2 weeks before dental attendance): Yes No

b) Will you question the patient on recent loss of taste or smell? Yes No

\section{REFERENCES}

1. Wu Y, Ho W, Huang Y, et al. SARS-CoV-2 is an appropriate name for the new coronavirus. Lancet. 2020;395(10228):949-950. doi: 10.1016/S0140-6736(20)30557-2. PMID: 32151324; PMCID: PMC7133598.

Full text links Free PMC Article PubMed Google Scholar Scopus WoS 2. World Health Organization. Statement on the second meeting of the International Health Regulations (2005) Emergency Committee regarding the outbreak of novel coronavirus (2019-nCoV) [Internet] 2020 [cited 2020 Dec 19]. Available from: https://www.who.int/ news/item/30-01-2020-statement-on-the-second-meeting of-the-international-health-regulations-(2005)-emergencycommittee-regarding-the-outbreak-of-novel-coronavirus-(2019ncov).

3. Worldometer. [Internet]. 2020 [cited 2020 Dec 19]. Available from: https://www.worldometers.info/coronavirus/

4. Vincent JH. Aerosol exposure: concepts, criteria, standards and applications. J Phys Conf. 2009; 151(1):012003. doi: 10.1088/1742$6596 / 151 / 1 / 012003$

Google Scholar Scopus WoS

5. Jamal M, Shah M, Almarzooqi SH, et al. Overview of transnational recommendations for COVID-19 transmission control in dental care settings. Oral Dis. 2020 May 19:10.1111/odi.13431. doi: 10.1111/odi.13431. PMID: 32428372; PMCID: PMC7280672. Full text links CrossRef PubMed Google Scholar WoS 6.Schwartz J, King CC, Yen MY. Protecting healthcare workers during the coronavirus disease 2019 (COVID-19) outbreak: lessons from Taiwan's severe acute respiratory syndrome response. Clin Infect Dis. 2020;71(15):858-860. doi: 10.1093/cid/ ciaa255. PMID: 32166318; PMCID: PMC7108122.

Full text links Free PMC Article CrossRef PubMed Google Scholar Scopus WoS

7. Sri Lanka Dental Association. Guidance to practice dentistry during COVID-19 outbreak. [Internet]. 2020 [cited 2020 Dec 19]. Available from: https://www.slda.lk/news-and-events/read/43guidance-to-practice-dentistry-during-covid-19-outbreak. 8. Centers for Disease Control and Prevention (CDC). Guidance for Dental Settings. Interim Infection Prevention and Control Guidance for Dental Settings During the Coronavirus Disease 2019 (COVID-19) Pandemic. [Internet]. 2020 [cited 2020 Dec 19]. Available from: https://www.cdc.gov/coronavirus/2019-ncov/hcp/dentalsettings.html 
9. Ahmed MA, Jouhar R, Ahmed N, et al. Fear and practice modifications among dentists to combat novel coronavirus disease (COVID-19) outbreak. Int J Environ Res Public Health. 2020;17(8):2821. doi: 10.3390/ijerph17082821. PMID: 32325888; PMCID: PMC7216192.

Full text links Free PMC Article CrossRef PubMed Google Scholar WoS

10. Khader Y, Al Nsour M, Al-Batayneh OB, et al. Dentists' awareness, perception, and attitude regarding COVID-19 and infection control: cross-sectional study among Jordanian dentists. JMIR Public Health Surveill. 2020;6(2):e18798. doi: 10.2196/18798. PMID: 32250959; PMCID: PMC7147327. Full text links Free PMC Article CrossRef PubMed Google Scholar Scopus WoS

11. Ministry of Health Sri Lanka. Medical Statistics Unit. Annual Health Bulletin 2018. [Internet]. 2021 [cited 2021 Jan 11]. Available from: http://www.health.gov.lk/moh_final/english/public/ elfinder/files/publications/AHB/2020/AHB 2018.pdf.

12. Duruk G, Gümüşboğa ZŞ, Çolak C. Investigation of Turkish dentists' clinical attitudes and behaviors towards the COVID-19 pandemic: a survey study. Braz Oral Res. 2020;34:e054. doi: 10.1590/1807-3107bor-2020.vol34.0054. PMID: 32490887. Full text links CrossRef PubMed Google Scholar Scopus
13. Chu DK, AkI EA, Duda S, et al; COVID-19 Systematic Urgent Review Group Effort (SURGE) study authors. Physical distancing, face masks, and eye protection to prevent person-to-person transmission of SARS-CoV-2 and COVID-19: a systematic review and meta-analysis. Lancet. 2020;395(10242):1973-1987. doi: 10.1016/S0140-6736(20)31142-9. PMID: 32497510; PMCID: PMC7263814.

Full text links Free PMC Article CrossRef PubMed Google Scholar 14. Centers for Disease Control and Prevention (CDC). Using Personal Protective Equipment (PPE). [Internet]. 2020 [cited 2020 Dec 19]. Available from: https://www.cdc.gov/coronavirus/2019ncov/hcp/using-ppe.html.

15. Kinariwala N, Samaranayake LP, Perera I, Patel Z. Concerns and fears of Indian dentists on professional practice during the coronavirus disease 2019 (COVID-19) pandemic. Oral Dis. 2020 Jun 7:10.1111/odi.13459. doi: 10.1111/odi.13459. PMID: 32506779; PMCID: PMC7300564.

Full text links Free PMC Article CrossRef PubMed Google Scholar Scopus WoS

\title{
Ruwan Duminda JAYASINGHE
}

BDS, MS, Professor

Department of Oral Medicine and Periodontology Faculty of Dental Sciences University of Peradeniya Peradeniya, 20400 Sri Lanka

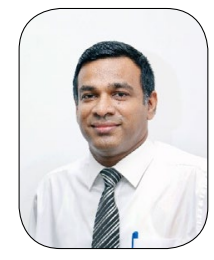

Ruwan Jayasinghe is currently working as the Chair Professor of Oral Medicine and Periodontology, Faculty of Dental Sciences, University of Peradeniya, Sri Lanka. He is a specialist in Oral Surgery/Medicine. He is the director to the Centre for Research in Oral Cancer. He has published more than 85 research papers in peer reviewed international and national journals. He is having more than 150 research presentations to his credit. For his research contributions, he has received multiple awards. He has authored or contributed to 09 books. He has delivered 05 orations, more than 50 guest lectures, both locally and internationally, acted as a resource person in workshops more than 150 times.

\section{Orestions}

\section{What is incubation period of COVID-19 infection?}

Da. 1-day;

ab. 2-3 days but may take up to 21 days;

ac. 28 days;

ad. 48 days.

\section{Which of the following is not a symptom of COVID-19 infection?}

口a. Fever;

ab. Dry cough;

c. Aches and pains;

$\square$ d. Sneezing.

\section{What will be the best method to control COVID-19 infection?}

$\square$ a. Social distancing;

ab. Hand hygiene;

ac. Wearing face masks;

d. All of above.

\author{
4. Which of the following groups are at a higher risk of getting COVID-19? \\ 口a. Infants; \\ ab.Yong; \\ ac. Middle aged; \\ $\square$ d. Elderly.
}

